Article

\title{
Erbium Ring Fiber Laser Cavity Based on Tip Modal Interferometer and Its Tunable Multi-Wavelength Response for Refractive Index and Temperature
}

\author{
Yanelis Lopez-Dieguez ${ }^{1}$, Julian M. Estudillo-Ayala ${ }^{1}$ (D), Daniel Jauregui-Vazquez ${ }^{1, *}$ (D), \\ Luis A. Herrera-Piad ${ }^{1}$ (D), Juan M. Sierra-Hernandez ${ }^{1}$, Diego F. Garcia-Mina ${ }^{2}$ (D), \\ Eloisa Gallegos-Arellano ${ }^{3}$, Juan C. Hernandez-Garcia ${ }^{1,4}$ and Roberto Rojas-Laguna ${ }^{1}$ \\ 1 Departamento de Electrónica, División de Ingenierías Campus Irapuato-Salamanca, Universidad de \\ Guanajuato, Carretera Salamanca-Valle de Santiago km $3.5+1.8$ km, Salamanca Gto. 36885, Mexico; \\ y.lopezdieguez@ugto.mx (Y.L.-D.); julian@ugto.mx (J.M.E.-A.); la.herrerapiad@ugto.mx (L.A.H.-P.); \\ jm.sierrahernandez@ugto.mx (J.M.S.-H.); jchernandez@ugto.mx (J.C.H.-G.); rlaguna@ugto.mx (R.R.-L.) \\ 2 Departamento de Física, Facultad de Ciencias Básicas, Universidad Autónoma de Occidente, \\ Calle 25 \# 115-85, Cali 760030, Colombia; dmina@uao.edu.co \\ 3 Departamento de Tecnologías de la Información y Comunicación, Universidad Tecnológica de Salamanca, \\ Avenida Universidad Tecnológica 200, Ciudad Bajío, Salamanca Gto. 36766, Mexico; \\ egallegos@utsalamanca.edu.mx \\ 4 Catedrático CONACYT, Consejo Nacional de Ciencia y Tecnología (CONACYT), Av. Insurgentes Sur \\ No. 1582, Col. Crédito Constructor, Del. Benito Juárez C.P. 039040, México \\ * Correspondence: jaureguid@ugto.mx; Tel.: +52-46-4647-9940 (ext. 2345)
}

Received: 29 June 2018; Accepted: 7 August 2018; Published: 10 August 2018

\begin{abstract}
A tunable multi-wavelength fiber laser is proposed and demonstrated based on two main elements: an erbium-doped fiber ring cavity and compact intermodal fiber structure. The modal fiber interferometer is fabricated using the cost-effective arc splice technique between conventional single-mode fiber and microfiber. This optical fiber structure acts as a wavelength filter, operated in reflection mode. When the refractive index and temperature variations are applied over the fiber filter, the ring laser cavity provides several quad-wavelength laser spectra. The multi-wavelength spectra are tuned into the C-band with a resolution of $0.05 \mathrm{~nm}$. In addition, the spectra are symmetric with minimal power difference between the lasing modes involved, and the average of the side mode suppression ratio is close to $37 \mathrm{~dB}$. This laser offers low-cost implementation, low wavelength drift, and high power stability, as well as an effect of easy controllability regarding tuned multi-wavelength.
\end{abstract}

Keywords: fiber laser; ring laser cavity; tunable multi-wavelength laser

\section{Introduction}

For several decades, the ability to generate tunable or switched multi-wavelength fiber lasers has been one of the focuses pursued by the fiber laser community. These lasers are associated with many reliable applications related to multi-wavelength spectra such as optical fiber sensors [1-9], spectroscopy systems [10], biomedical imaging [11], telecommunications [12], microwave photonics [13], and radio frequency optical domain systems [14]. These applications require achieving compact configuration, stable emission, narrow linewidth, and adequate spacing mode. All these features prevent crosstalk, error measurement, and low resolution. To this end, many methods have been proposed, most of them based on fiber interferometers (Fabry-Perot, Mach-Zehnder, Michelson, and Sagnac) [15-19], comb filters [20,21], Raman effect [20], Brillion scattering [22,23], nonlinear loop mirrors [24], saturable optical absorber elements [25,26], and extrinsic interferometers [27]. 
These proposed schemes offer compactness, high power stability, minimal wavelength drift, and adequate signal-to-noise ratio, long operation time, and low threshold. Furthermore, some research groups have demonstrated the capability of tunable multi-wavelength [28-33]. The most common techniques to overcome modal competition and achieve multi-wavelength spectra are Four-Wave Mixing (FWM) and Stimulated Brillouin Scattering (SBS). However, these techniques require several meters of highly nonlinear fiber optics, and polarization plays an important role; this entails complex configurations and costly implementation. Moreover, in some arrangements, the multi-wavelength tuning effect undergoes lasing power disparity, small side mode suppression ratio, and power dependence. One of the most common setups used to overcome the undesired effect is the recognized ring fiber laser cavity based on modal fiber interferometers [26-38].

In this work, a cost-effective modal interferometer and simple ring laser cavity are used to demonstrate the multi-wavelength effect. The laser arrangement was governed by a modal fiber structure operated in reflection mode; the structure was set into an erbium fiber ring laser cavity, resulting in a quad-wavelength laser. This initial laser spectrum had a wavelength drift of around $0.008 \mathrm{~nm}$ and power variations of $0.46 \mathrm{~dB}$. The refractive index and thermal variations around the modal interferometers were assessed to provide a simple method for tuning multi-wavelength spectra. The spectrum was analyzed when refractive index changes were applied around the fiber filter; here, two dual-wavelength spectra were tuned with a resolution of $0.05 \mathrm{~nm}$. Minimal power and wavelength variations were observed through the tuned range. To assess the thermal effect, a temperature exceeding $90^{\circ} \mathrm{C}$ was applied over the fiber filter, tuning dual and triple wavelength spectra. Most of the spectra achieved had an adequate side mode suppression ratio, high peak level, lower wavelength drift, and minimal power variation.

\section{Fiber Filter Fabrication and Its Principle Operation}

The modal fiber interferometer (MFI) was fabricated by using the arc splice technique, where the catastrophic splicing of an optical microfiber ( $<60 \mu \mathrm{m}$ diameter) at the tip of conventional single-mode fiber $(125 \mu \mathrm{m}$ diameter) is performed. The microfiber used in this work was fabricated using the drawing flame technique [39]. During the fabrication process, only an arc splicer (Fitel S175, Furukawa FITEL Optic Products Co., Ltd., Peachtree, GA, USA) was used in manual mode, setting the single-mode fiber default program to the following parameters: power $94 \mathrm{~A} . \mathrm{U}$ and $\mathrm{Z}$ push distance $11 \mu \mathrm{m}$. Both fibers were cleaved, set, and aligned into the splicer machine; then, ten discharges were applied until a first catastrophic splice zone (Z1) was achieved (Figure 1). Zone Z1 was translated at a specific distance from the electrodes, and the microfiber was exposed at the electrode's area; then, several discharges are applied to cut the microfiber ( $\leq 18$ discharges). As a result, the second catastrophic zone, Z2, was obtained; the final structure can be observed in Figure 1. The Z1 and Z2 collapse regions had a size of $50 \mu \mathrm{m}$ (this value was estimated using the arc splicer). The distance, $\mathrm{D}$, between $\mathrm{Z1}$ and Z2 oscillated between $400 \mu \mathrm{m}$ and $500 \mu \mathrm{m}$. The fabrication process was monitored in real-time to minimize the insertion loss. Hence, the number of discharges varied, considering the minimal insertion loses; consequently, the distance, D, was also affected.

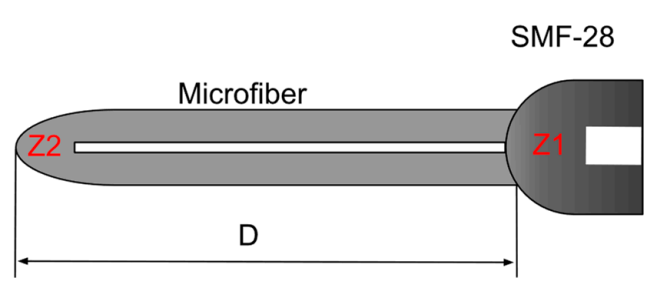

(a)

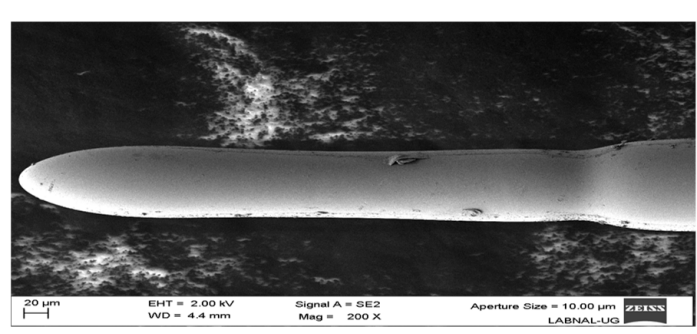

(b)

Figure 1. Physical characteristics of the MFI structure: (a) structure diagram; (b) Scanning Electron Microscope Image (SEM) of the structure. 
The MFI was operated in reflection mode; its interference spectrum is shown in Figure 2a. The spectrum showed visibility oscillating between $8 \mathrm{~dB}$ and $10 \mathrm{~dB}$; its free spectral range was $1.6 \mathrm{~nm}$. The Fourier transform was applied to the reflection interference spectrum to identify the modal contribution (see Figure $2 b$ ). The fundamental reflected core mode is considered the peak centered at $0 \mathrm{~nm}^{-1}$. Two spatial frequency regions with some intensity peaks can be seen; these modal energies correspond to higher-order reflection modes. All the modes described above are excited by several refractive index interfaces located at zones $Z 1$ and $Z 2$. The first refractive index interface can be found at the $\mathrm{Z} 1$ zone, where the bulk of the collapsed material and the core and cladding of the fibers involved produces a refractive index change. At this point, part of the light arriving at the Z1 zone is reflected, and the rest travels through the microfiber. The light then travels to the Z2 zone, where the tip of the bulk collapsed material, and the surrounding medium produces a refractive index interface, resulting in the generation of some reflections.

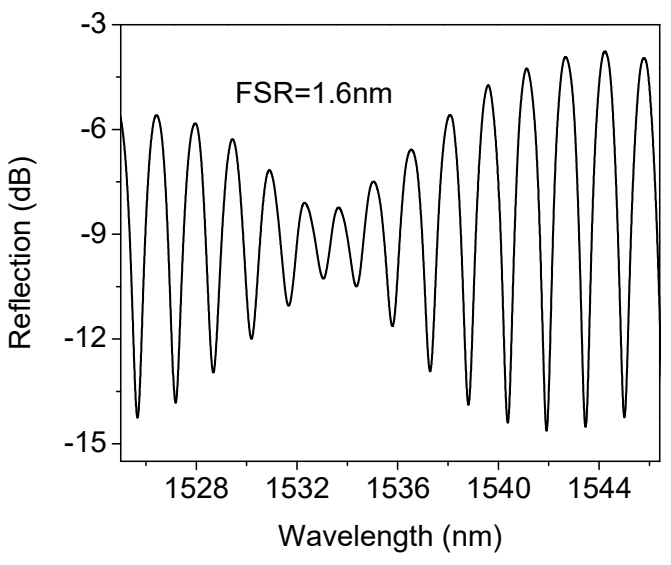

(a)

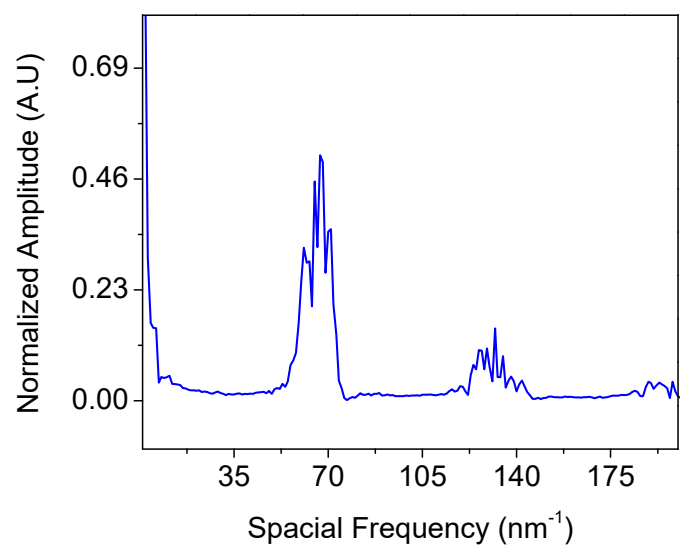

(b)

Figure 2. MFI characterization: (a) Reflection spectrum of the used MFI obtained using a broadband source at port 1 of an optical fiber circulator (OFC), the questioned MFI at port 2 of the OFC, and the OSA at port 3; (b) Spatial frequency analysis of the reflection interference spectrum.

The amplitude of the total reflected electric vector can be described by [40]:

$$
E_{R}=\left[\sqrt{R_{1}}+\sum_{k=1}^{n}\left(e^{-2 j\left(\sum_{i=1}^{k} \varnothing_{i}\right)} \sqrt{R_{k+1}} \prod_{i=1}^{k}\left(1-R_{i}\right)\right)\right] E_{0}
$$

each reflectivity can be determined by the relation $R=\left|\left(n_{x}-n_{y}\right)\left(n_{x}+n_{y}\right)\right|^{2}$; here, $n_{x}$ and $n_{y}$ represent the effective refractive index involved. $R_{1}$ is the first reflection and $R_{k+1}$ represents the other reflections gene rated by the structure. The phase between the reflected modes generated is $\varnothing_{i}=(4 \pi d n / \lambda)$, where $\lambda$ is the operation's wavelength, $d$ is the distance of the optical path and $n$ is the effective refractive indexes of the different zones. More detailed information is presented in reference [41].

\section{Results}

The proposed MFI structure was set into the ring fiber laser cavity. This arrangement consisted of a pump laser diode (QPHOTONICS QDFBLD-980-500); its signal was incorporated into the ring laser cavity by using an optical fiber wavelength division multiplexer (WDM). By using the $980 \mathrm{~nm}$ port, the pumped signal was launched to the gain medium ( $4.5 \mathrm{~m}$ of erbium-doped fiber), thus, generating an amplified spontaneous emission (ASE). At the end of the erbium-doped fiber length, a polarization controller (PC) was set using the following configuration: quarter wave plate-half wave plate -quarter wave plate (QWP-HWP- QWP). The purpose of the plates was to increase the system's 
stability. The ASE spectrum was launched to the MFI using an optical fiber circulator (OFC); at this point, the reflected signal from the MFI was reincorporated into the ring cavity by using port 3 of the OFC. The interference reflection spectrum from the MFI traveled to the optical fiber coupler 90:10. Here, the $10 \%$ coupler port, which was connected to an optical spectrum analyzer (OSA, AQ6370 Yokogawa China Co., Ltd., Tokyo, Japan), monitored the output laser. The $90 \%$ signal was launched to an optical fiber isolator, which provided a path into the cavity. Lastly, the fiber isolator output and the $1550 \mathrm{~nm}$ WDM port were spliced to close the ring cavity. The ring fiber laser cavity is shown in Figure 3.

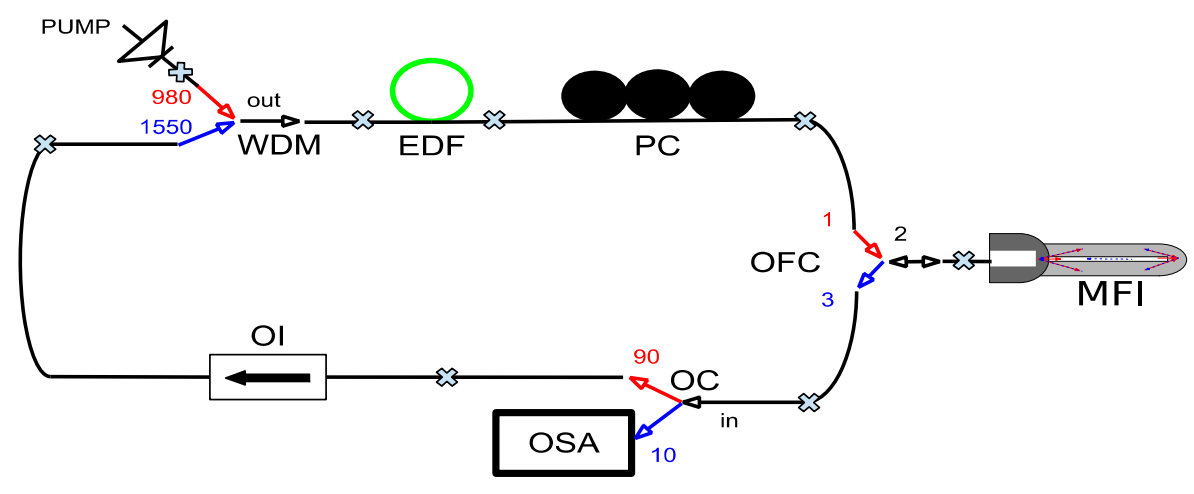

Figure 3. Experimental setup of the ring cavity laser. WDM: wavelength division multiplexer, EDF: erbium-doped fiber, PC: polarization controller, OFC: optical fiber circulator, OC: optical coupler, OSA: optical spectrum analyzer, OI: optical isolator.

The pumping diode was set at $400 \mathrm{~mA}$, achieving the spectrum shown in Figure 4a; it is important to stress that a lower current threshold was observed (70 mA). Four lasing lines constituted the initial laser response. This spectrum had three consecutive lasing emissions, one single line separated from the triple emission by $11.7 \mathrm{~nm}$. The strong relationship between the laser emission and the interference spectrum of the optical filter is well recognized; in our work, this was governed by the MFI. According to the filter spectrum, the region with lower visibility did not have laser emissions (see Figure 4a); moreover, the emissions were centered at the peak interference fringe. The triple-laser emission was made up of peak wavelengths centered at $1527.9949 \mathrm{~nm}$ (P1), $1529.4903 \mathrm{~nm}$ (P2), and $1531.0256 \mathrm{~nm}$ (P3).

The spacing mode of the initial multi-wavelength spectrum was $1.6 \mathrm{~nm}$; this value corresponds to the free spectral range of the interference spectrum generated by the MFI. The power peaks from the triple-laser emission were: $-26.1580 \mathrm{dBm}(\mathrm{P} 1),-16.7160 \mathrm{dBm}(\mathrm{P} 2)$, and $-22.9010 \mathrm{dBm}$ (P3). The side mode suppression ratio (SMSR) values were: $33 \mathrm{~dB}$ (P1), $43 \mathrm{~dB}$ (P2), and $35 \mathrm{~dB}$ (P3). The single-lasing line (P4) had the following characteristics: wavelength centered at $1542.75 \mathrm{~nm}$, power peak of $-19.85 \mathrm{dBm}$, and SMSR around $41 \mathrm{~dB}$. The stability of the fiber laser was analyzed; the laser spectrum was recorded every $3 \mathrm{~min}$ for an $\mathrm{h}$. The centered wavelength and peak power variations are shown in Figure $4 \mathrm{~b}$. As can be observed, the proposed fiber laser presents minimal wavelength variations around $0.008 \mathrm{~nm}$ for P3 and P4 and maximal for P2 $(0.02 \mathrm{~nm})$. The minimal power fluctuations were observed at $\mathrm{P} 2(0.46 \mathrm{~dB})$, while the maximal intensity fluctuations were presented at P1 $(2.5 \mathrm{~dB})$. The initial laser spectrum presented high wavelength stability. It must be noted that the laser results shown above correspond to the room's temperature, which was around $25^{\circ} \mathrm{C}$, and the MFI air-suspended (1.00 RIU). 


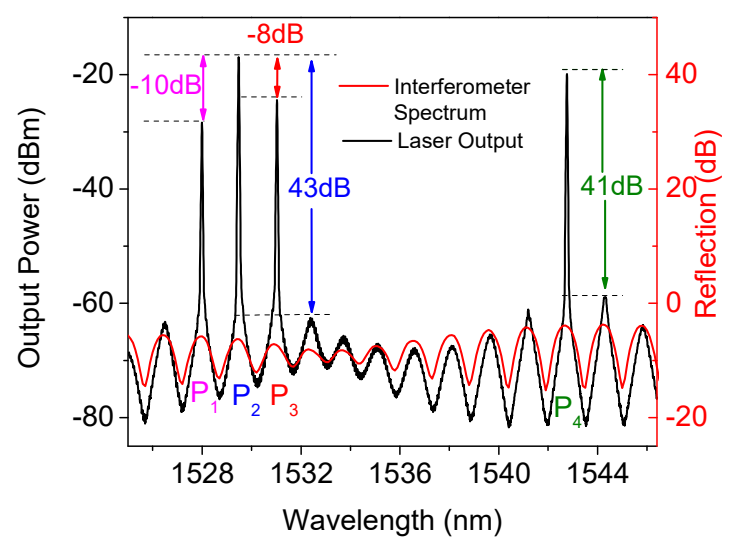

(a)

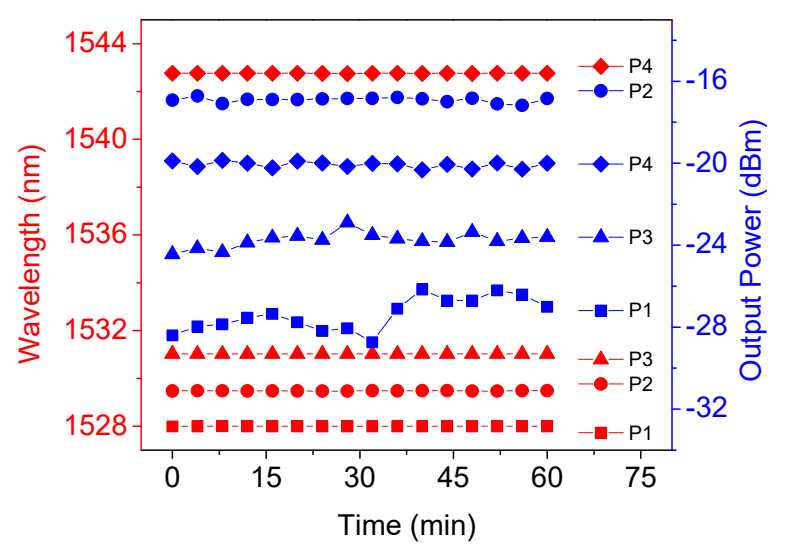

(b)

Figure 4. Laser emission: (a) Quadruple-wavelength laser emission output for the initial ring cavity configuration (black line). Unequivocal correspondence between the laser emission (black line) and the MFI reflection spectrum (red line); (b) One-hour laser emission wavelength stability assessment (red) and power (blue).

\subsection{Refractive Index Response}

The fiber laser response was analyzed when liquid refractive index variations were applied around the MFI. We set an initial refractive index close to 1.332 RIU (distilled water), obtaining the laser spectra shown in Figure 5. The P1, P2, and P4 laser peaks underwent insignificant wavelength variations $(0.4 \mathrm{~nm})$, and a new laser peak was obtained, which had the following characteristics: centered wavelength at $1543.79 \mathrm{~nm}$ (P5), a peak power of $-21.25 \mathrm{dBm}$, and SMSR exceeding $30 \mathrm{~dB}$. Two dual-wavelength emissions comprised this quadruple-laser spectrum, both of them separated $13.2 \mathrm{~nm}$; thus, each dual emission had a mode offset of $1.6 \mathrm{~nm}$. This spectrum was analyzed during an hour, evaluating the wavelength and peak power fluctuations (Figure 5b). According to the data, the P1 and P3 lasing modes had power fluctuations exceeding $7 \mathrm{~dB}$. However, the P2 and P5 peaks exhibited lower power fluctuations. Additionally, the quadruple-laser spectrum had minimal wavelength variations $(<0.1 \mathrm{~nm})$. The power instabilities observed can be adjusted by using the PC. Other techniques, such as nonlinear optical loop mirror and nonlinear fiber optics can also be implemented to reduce these variations [42,43]. However, these techniques will modify the fiber laser response.

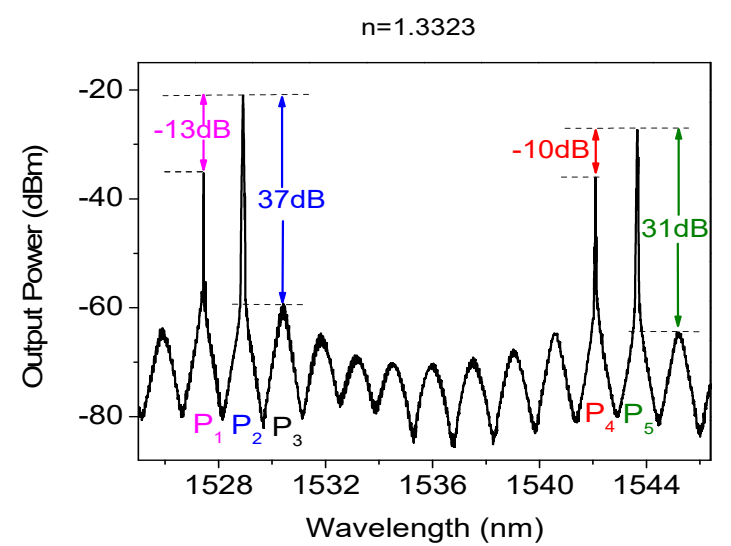

(a)

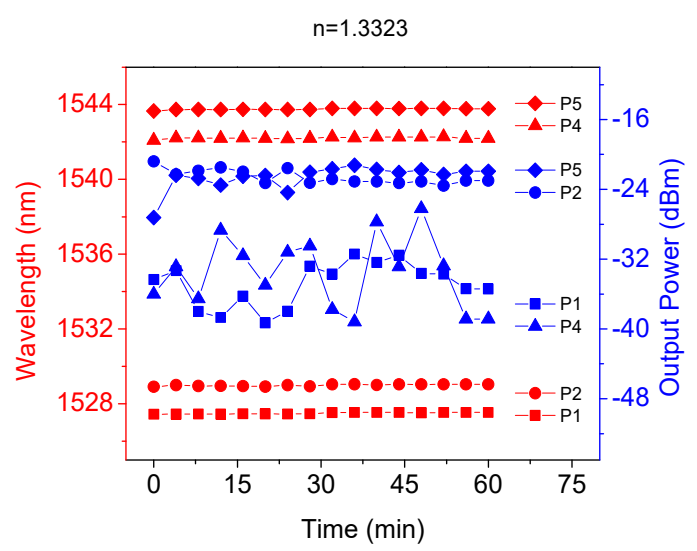

(b)

Figure 5. Refractive index response: (a) Quadruple-wavelength laser emission output for distilled water immersion (RIU 1.332); (b) Stability analysis for refractive index surrounding alteration (wavelength (red) and power (blue)). 
Different water-glycerin mixtures were used to increase the liquid refractive index around the MFI; their values were estimated using a Refracto 30GS refractometer. The refractive index ranged from 1.3323 to 1.3799 RIU; the minimal variation between each sample was 0.003 RIU. When the liquid refractive index was increased around the MFI, the laser response was consistently altered across the wavelength range shown in Figure 6a. It is important to stress that, typically, multi-wavelength fiber laser arrangement exhibit switched lasing mode when any physical effect perturbs the optical fiber filter. However, our experimental results showed that the entire spectrum displayed a constant wavelength shift to a longer wavelength when linear refractive index increments were applied.

By considering the total wavelength shifting, the following tuning parameters can be estimated: $15.71 \mathrm{~nm} /$ RIU (P1) $14.33 \mathrm{~nm} /$ RIU (P2), $16.13 \mathrm{~nm} / \mathrm{RIU}$ (P4), and $13.77 \mathrm{~nm} / \mathrm{RIU}$ (P5) (Figure 6b). Moreover, the following high linear wavelength shifting responses were presented: $R^{2}=0.97609(\mathrm{P} 1)$, $R^{2}=0.98706(P 2) R^{2}=0.98426(P 3)$, and $R^{2}=0.8756(P 4)$ (Figure 6b). It was also observed that the peaks had different dynamic ranges; for instance, the P5laser peak disappeared for refractive index variations exceeding 1.3476, while, $\mathrm{P} 2$ and $\mathrm{P} 4$ were present in almost all the refractive index ranges.

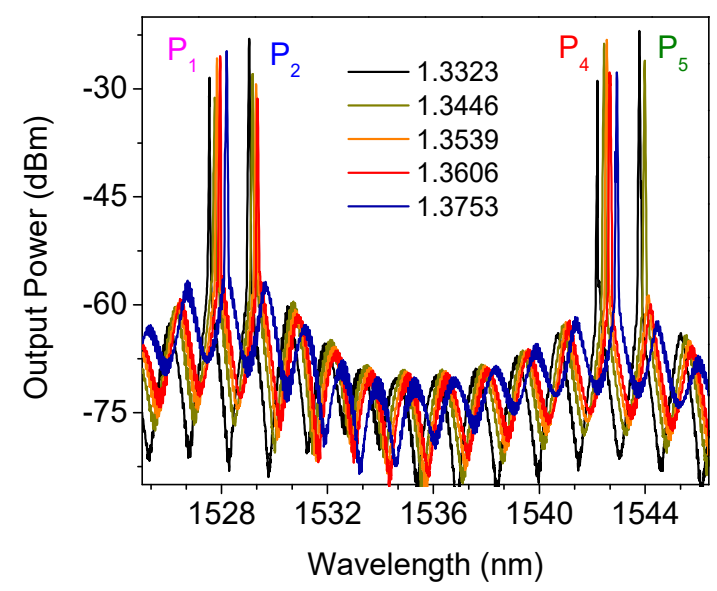

(a)

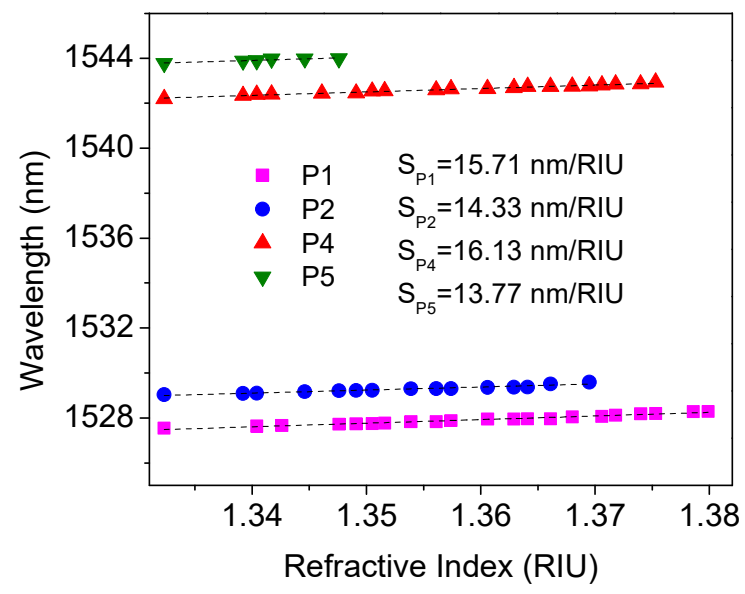

(b)

Figure 6. Refractive index response: (a) Laser emission response for refractive index ranging from 1.3323 to 1.3757 RIU; (b) Refractive index data analysis for lasing modes observed.

The dynamic range variation is strongly related to the refractive index interference pattern response of the MFI. Here, when the refractive index was applied, the interference pattern underwent a wavelength shift, as well as a visibility decrement [41]; as a result, some peaks start to disappear as the visibility is reduced. These responses were strongly related to the frequencies generated by the MFI (Figure 2b), some of these frequencies disappeared as the refractive index increased [41]; hence, the lasing modes obtained had different dynamic ranges. The P2 peak was selected for the loop hysteresis analysis because of its minimal power and wavelength fluctuations (Figure 7). The lower hysteresis can be attributed to features such as room temperature changes, pumping diode fluctuations, and birefringence changes induced by optical fiber bending. 


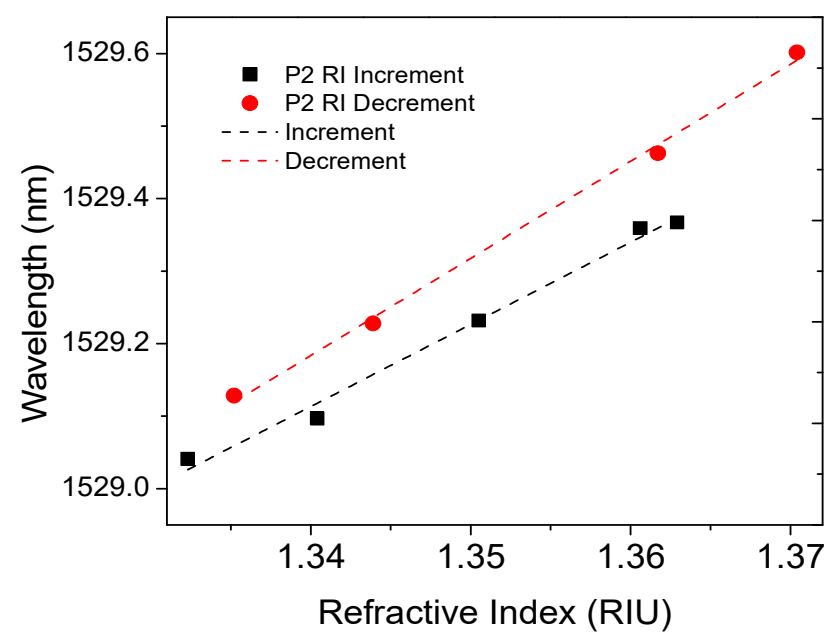

Figure 7. Loop hysteresis analysis for refractive index variation using the P2 peak.

\subsection{Temperature Analysis}

To analyze the temperature effects in the fiber laser, the MFI was set over a hotplate, and the temperature was varied from $90^{\circ} \mathrm{C}$ to $210^{\circ} \mathrm{C}$. This range responded to the cross-sensitivities presented by the MFI [41], which requires temperatures over $100{ }^{\circ} \mathrm{C}$ to recognize thermal effects. The laser spectrum at $90{ }^{\circ} \mathrm{C}$ was comprised of triple-laser emissions. For P2 and P3, the spacing mode between them was around 1.6nm and separated $13.23 \mathrm{~nm}$ from a new laser emission, P6, which was centered at $1543.33 \mathrm{~nm}$. The laser emissions had the following SMSR: $37 \mathrm{~dB}(\mathrm{P} 2), 41 \mathrm{~dB}(\mathrm{P} 3)$, and $43 \mathrm{~dB}(\mathrm{P} 6)$. Their peak wavelengths were $-23.40 \mathrm{dBm}(\mathrm{P} 2),-19.19 \mathrm{dBm}(\mathrm{P} 3)$, and $-17.04 \mathrm{dBm}(\mathrm{P} 6)$. The fiber laser's response to temperature can be seen in Figure 8. The increase in temperature produces a shifting response in the multi-wavelength. However, at $145^{\circ} \mathrm{C}$, the laser spectrum becomes a quadruple-laser emission; this new spectrum is comprised of P2, P3, P5, and P6. As we increase the temperature, some peaks, such as P2, P5, and P6 continue shifting to longer wavelengths. At the same time, other laser emissions start to appear, such as P1 and P0 (wavelength centered at $1528.86 \mathrm{~nm}(\mathrm{P} 0)$ and $1530.33 \mathrm{~nm}$ (P1), peak wavelength $-23.08 \mathrm{dBm}(\mathrm{P0})$ and $-20.02 \mathrm{dBm}(\mathrm{P} 1)$, and SMSR of $38 \mathrm{~dB}(\mathrm{P} 0)$ and $41 \mathrm{~dB}(\mathrm{P} 1)$ at $\left.210{ }^{\circ} \mathrm{C}\right)$.

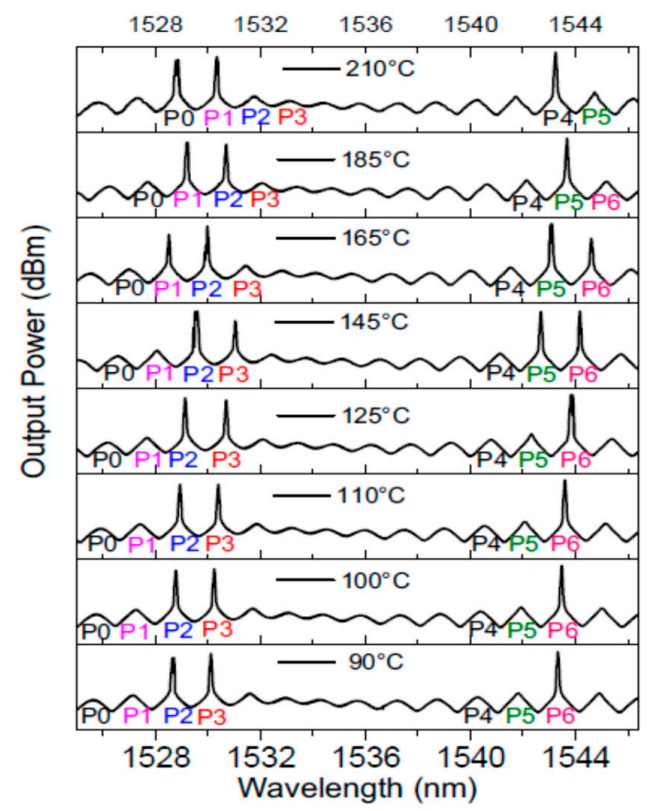

Figure 8. Laser emission response for temperature variation from $90{ }^{\circ} \mathrm{C}$ to $210{ }^{\circ} \mathrm{C}$. 
In analyzing peaks $\mathrm{P} 2, \mathrm{P} 3$, and $\mathrm{P} 6$, the following thermal-wavelength relations can be expected: $21.01 \mathrm{pm} /{ }^{\circ} \mathrm{C}(\mathrm{P} 2), 16.99 \mathrm{pm} /{ }^{\circ} \mathrm{C}(\mathrm{P} 3)$, and $16.97 \mathrm{pm} /{ }^{\circ} \mathrm{C}(\mathrm{P} 6)$, as well as adequate linear responses of 0.96306 (P2), 0.99507 (P3), and 0.9890 (P6). As can be observed in Figure 9 the dynamic range is different for each peak; however, the temperature variations generated different triple or quadruple spectra. The tunable multi-wavelength effect is only presented in the range from $90{ }^{\circ} \mathrm{C}$ to $125^{\circ} \mathrm{C}$. According to the MFI temperature's analysis, the visibility remained almost constant and only presented wavelength shifting. As a result, the multi-wavelength shifting range was shorter than the one presented in the refractive index analysis. The appearance of other lasing modes was evident as the temperature increased because of the modal competitions was similar for all the lasing modes involved. It is well recognized that fiber-optic interferometers exhibit a suitable sensitivity for refractive index and temperature variations [44]; however, the ring laser cavity represents an alternative method to extract phase information [1-9].

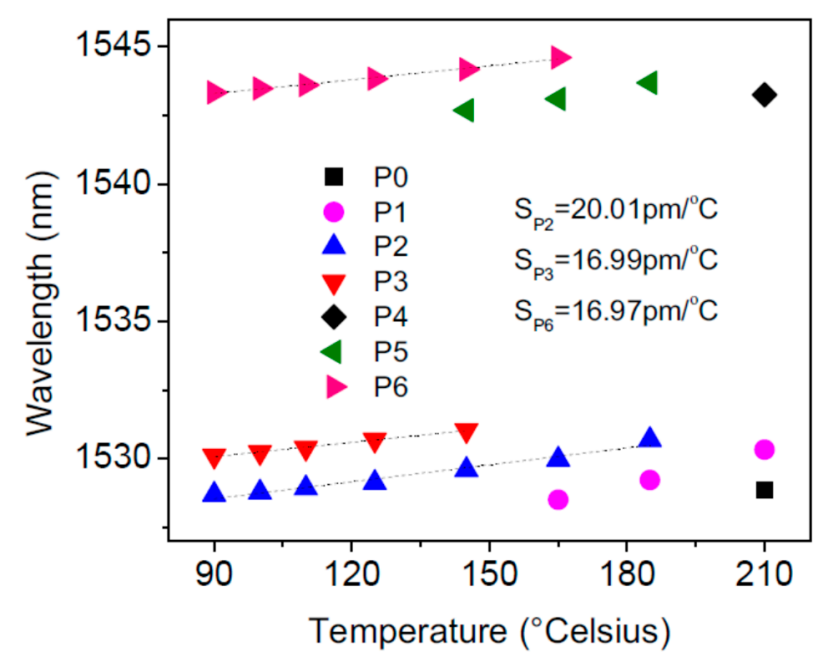

Figure 9. Temperature data analysis for peaks P0 to P6. Temperature-wavelength response for peaks P2, P3, and P6.

\section{Discussion}

Based on the results, we identified two simple methods to tune multi-wavelength laser spectra generated by a modal fiber-optic interferometer. Most of the features observed in the laser response depend on the modal interferometer; this one was fabricated using a cost-effective technique involving inexpensive fibers (conventional single-mode fiber and microfiber). In this technique, the fiber structure acts as a fiber filter into the erbium ring laser cavity. The initial laser spectrum is comprised of four lasing lines (a triple consecutive laser emission and one single-lasing line), where lower wavelengths drift $(0.008 \mathrm{~nm})$ and minimal power variations of $0.46 \mathrm{~dB}$ were observed. When the modal interferometer is immersed in distilled water (initial refractive index value), we observed four lasing modes: two dual laser emissions separated $13.2 \mathrm{~nm}$, with a spacing mode of $1.6 \mathrm{~nm}$, and wavelengths variations lower than $0.1 \mathrm{~nm}$. When the refractive index is increased, the entire quad-laser spectrum is tuned, resulting in a tunable resolution of $0.05 \mathrm{~nm}$. According to the hysteresis analysis, this laser offers minimal wavelength variation when it is operated in a forward and backward refractive index direction. Besides, according to the results the refractive index variations generate a $2 \mathrm{~nm}$ tuned range, this range can be compared with other works $[33,45,46]$. Here, it is important to stress that despite the higher tuning range previously reported $[27,29,32,33,45-49]$, some works present irregular spectra, strong relation between the number lasing modes and the tuned step, lower resolution, and higher wavelength drift. The temperature response shows tunable multi-wavelength responses for different multi-wavelength laser spectra; the resolution is similar to that observed in refractive index analysis. However, temperature increments must exceed $90{ }^{\circ} \mathrm{C}$; minimal temperature variations 
will result in lower resolutions. According to the results and considering the high sensitivity of the interferometers [44], the proposed scheme can also be an alternative method to detect temperature and refractive indexes using a signal acquisition system, which, based on a near-infrared photodetector, can reduce the cost for sensing applications. Moreover, the fiber laser arrangement can be used for remote sensing applications. Despite the power instabilities observed, the laser offers better performance than some works $[14,18]$. The laser presented in this work is an alternative, cost-effective setup for tuning multi-wavelength spectra using simple and easy-to-control techniques.

Author Contributions: Conceptualization, Y.L.-D. and D.J.-V.; Methodology, D.J.-V. and J.M.S.-H.; Validation, J.M.E.-A., and J.C.H.-G.; Formal Analysis, D.F.G.-M., D.J.-V., Y.L.-D. and L.A.H.-P.; Investigation, Y.L.-D.; Resources, J.M.E.-A., and R.R.-L.; Data Curation, Y.L.-D., E.G.-A.; Writing-Original Draft Preparation, D.F.G.-M., D.J.-V.; Writing-Review \& Editing, D.J.-V.; Visualization, D.J.-V., J.M.S.-H., Y.L.-D. and L.A.H.-P.; Supervision, J.M.E.-A., and R.R.-L.; Project Administration, J.M.E.-A., and R.R.-L.; Funding Acquisition, J.M.E.-A., and D.J.V.

Funding: This research was funded by CONACYT, grant number [577494/307127], and the Dirección de Apoyo a la Investigación y al Posgrado [UGTO-DAIP CIIC 283/2018].

Acknowledgments: We would like to thank to the National Lab UG for the micrographs.

Conflicts of Interest: The authors declare no conflict of interest.

\section{References}

1. Yin, Z.; Gao, L.; Liu, S.; Zhang, L.; Wu, F.; Chen, L.; Chen, X. Fiber Ring Laser Sensor for Temperature Measurement. J. Lightw. Technol. 2010, 28, 3403-3408. [CrossRef]

2. Xu, Y.; Zhang, M.; Lu, P.; Mihailov, S.; Bao, X. Multi-parameter sensor based on random fiber lasers. AIP Adv. 2016, 6, 95009. [CrossRef]

3. Liu, Z.; Li, Y.; Liu, Y.; Tan, Z.-W.; Jian, S. A Static Axial Strain Fiber Ring Cavity Laser Sensor Based on Multi-Modal Interference. IEEE Photonics Technol. Lett. 2013, 25, 2050-2053. [CrossRef]

4. Bai, X.; Fan, D.; Wang, S.; Pu, S.; Zeng, X. Strain Sensor Based on Fiber Ring Cavity Laser With Photonic Crystal Fiber In-Line Mach-Zehnder Interferometer. IEEE Photonics J. 2014, 6, 1-8. [CrossRef]

5. Gonzalez-Reyna, M.A.; Alvarado-Mendez, E.; Estudillo-Ayala, J.M.; Vargas-Rodriguez, E.; Sosa-Morales, M.E.; Sierra-Hernandez, J.M.; Jauregui-Vazquez, D.; Rojas-Laguna, R. Laer Temperature Sensor Based on a Fiber Bragg Grating. IEEE Photonics Technol. Lett. 2015, 27, 1141-1144. [CrossRef]

6. Sun, C.; Dong, Y.; Wang, M.; Jian, S. Liquid level and temperature sensing by using dual-wavelength fiber laser based on multimode interferometer and FBG in parallel. Opt. Fiber Technol. 2018, 41, 212-216. [CrossRef]

7. Liang, L.; Ren, G.; Yin, B.; Peng, W.; Liang, X.; Jian, S. Refractive Index and Temperature Sensor Based on Fiber Ring Laser with STCS Fiber Structure. IEEE Photonics Technol. Lett. 2014, 26, 2201-2204. [CrossRef]

8. Liu, Z.; Tan, Z.; Yin, B.; Bai, Y.; Jian, S. Refractive index sensing characterization of a singlemodecladdingless-singlemode fiber structure based fiber ring cavity laser. Opt. Express 2014, 22, 5037. [CrossRef] [PubMed]

9. Zhang, Q.; Chang, J.; Wang, Q.; Wang, Z.; Wang, F.; Qin, Z. Acousto-Optic Q-Switched Fiber Laser-Based Intra-Cavity Photoacoustic Spectroscopy for Trace Gas Detection. Sensors 2017, 18, 42. [CrossRef] [PubMed]

10. Allen, T.J.; Beard, P.C. Pulsed near-infrared laser diode excitation system for biomedical photoacoustic imaging. Opt. Lett. 2006, 31, 3462. [CrossRef] [PubMed]

11. Boroon, M.; Hitam, S.; Mahdi, M.A.; Sahbudin, R.K.Z.; Seyedzadeh, S. Performance of Multi-Wavelength Erbium Doped Fiber Laser on Free Space Optical Medium. In Proceedings of the IEEE 5th International Conference on Photonics, Kuala Lumpur, Malaysia, 2-4 September 2014; pp. 2-4.

12. Xu, D.; Cao, Y.; Zhao, A.; Tong, Z. A microwave photonic filter based on multi-wavelength fiber laser and infinite impulse response. Optoelectron. Lett. 2016, 12, 325-328. [CrossRef]

13. Wang, C.; Yao, J. Fiber Bragg gratings for microwave photonics subsystems. Opt. Express 2013, $21,22868$. [CrossRef] [PubMed]

14. Jauregui-Vazquez, D.; Rojas-Laguna, R.; Estudillo-Ayala, J.M.; Hernandez-Garcia, J.C.; Lopez-Dieguez, Y.; Sierra-Hernandez, J.M. A multi-wavelength erbium-doped fiber ring laser using an intrinsic Fabry-Perot interferometer. Laser Phys. 2016, 26, 105105. [CrossRef] 
15. He, W.; Zhu, L.; Dong, M.; Lou, X.; Luo, F. Wavelength-switchable C-band erbium-doped fibre laser incorporating all-fibre Fabry-Perot interferometer fabricated by chemical etching. J. Mod. Opt. 2018, 65, 818-824. [CrossRef]

16. Sierra-Hernandez, J.M.; Rojas-Laguna, R.; Vargas-Rodriguez, E.; Estudillo-Ayala, J.M.; Jauregui-Vazquez, D.; Guzmán-Chávez, A.D.; Zaca-Moran, P. A tunable multi-wavelength erbium doped fiber laser based on a Mach-Zehnder interferometer and photonic crystal fiber. Laser Phys. 2013, 23, 125103. [CrossRef]

17. Mirza, M.A.; Stewart, G. Theory and design of a simple tunable Sagnac loop filter for multiwavelength fiber lasers. Appl. Opt. 2008, 47, 5242-5252. [CrossRef] [PubMed]

18. Salceda-Delgado, G.; Martinez-Rios, A.; Sierra-Hernandez, J.M.; Rodríguez-Carreón, V.C.; Toral-Acosta, D.; Selvas-Aguilar, R.; Álvarez-Tamayo, R.I.; Castillo-Guzman, A.A.; Rojas-Laguna, R. Reconfiguration of the multiwavelength operation of optical fiber ring lasers by the modifiable intra-cavity induced losses of an in-fiber tip probe modal Michelson interferometer. Laser Phys. 2018, 28, 035107. [CrossRef]

19. Chow, J.; Town, G.; Eggleton, B.; Ibsen, M.; Sugden, K.; Bennion, I. Multiwavelength generation in an erbium-doped fiber laser using in-fiber comb filters. IEEE Photonics Technol. Lett. 1996, 8, 60-62. [CrossRef]

20. Sun, G.; Moon, D.S.; Lin, A.; Han, W.-T.; Chung, Y. Tunable multiwavelength fiber laser using a comb filter based on erbium-ytterbium co-doped polarization maintaining fiber loop mirror. Opt. Express 2008, 16, 3652. [CrossRef] [PubMed]

21. Han, Y.G.; Kim, C.S.; Kang, J.U.; Paek, U.C.; Chung, Y. Multiwavelength Raman fiber-ring laser based on tunable cascaded long-period fiber gratings. IEEE Photonics Technol. Lett. 2003, 15, 383-385. [CrossRef]

22. Zhang, Z.X.; Xu, K.; Wu, J.; Hong, X.B.; Lin, J.T. Multiwavelength figure-of-eight fiber laser with a nonlinear optical loop mirror. Laser Phys. Lett. 2008, 5, 213-216. [CrossRef]

23. Zhang, L.; Xu, Y.; Lu, P.; Mihailov, S.; Chen, L. Multi-Wavelength Brillouin Random Fiber Laser via Distributed Feedback from a Random Fiber Grating. J. Lightw. Technol. 2018, 36, 2122-2128. [CrossRef]

24. Liu, J.; Yao, J.; Yao, J.; Yeap, T.H. Single-longitudinal-mode multiwavelength fiber ring laser. IEEE Photonics Technol. Lett. 2004, 16, 1020-1022. [CrossRef]

25. Liu, X.; Han, D.; Sun, Z.; Zeng, C.; Lu, H.; Mao, D.; Cui, Y.; Wang, F. Versatile multi-wavelength ultrafast fiber laser mode-locked by carbon nanotubes. Sci. Rep. 2013, 3, 2718. [CrossRef] [PubMed]

26. Yeh, C.H.; Chow, C.W.; Wu, Y.F.; Shih, F.Y.; Wang, C.H.; Chi, S. Multiwavelength erbium-doped fiber ring laser employing Fabry-Perot etalon inside cavity operating in room temperature. Opt. Fiber Technol. 2009, 15, 344-347. [CrossRef]

27. Lee, H.J.; Kim, S.-J.; Ko, M.O.; Kim, J.-H.; Jeon, M.Y. Tunable, multiwavelength-swept fiber laser based on nematic liquid crystal device for fiber-optic electric-field sensor. Opt. Commun. 2018, 410, 637-642. [CrossRef]

28. Ummy, M.A.; Madamopoulos, N.; Dorsinville, R. Tunable multi-wavelength SOA based linear cavity fiber laser source for optical communications applications. In Proceedings of the 2011 International Conference on Communications and Information Technology (ICCIT), Venice, Italy, 27-29 April 2011; pp. 87-91.

29. Li, Y.; Tian, J.; Quan, M.; Yao, Y. Tunable Multiwavelength Er-Doped Fiber Laser with a Two-Stage Lyot Filter. IEEE Photonics Technol. Lett. 2017, 29, 287-290. [CrossRef]

30. He, W.; Li, D.; Zhu, L.; Dong, M.; Luo, F. Tunable Multiwavelength Erbium-Doped Fiber Laser Employing PM-FBG and Mach-Zehnder Interferometer with Optical Fiber Delay Line. IEEE Photonics J. 2017, 9, 1-8. [CrossRef]

31. Xiao, F.; Alameh, K.; Lee, Y.T. Tunable multi-wavelength fiber lasers based on an Opto-VLSI processor and optical amplifiers an Opto-VLSI processor and optical amplifiers. Opt. Express 2009, 17, 910-912. [CrossRef] [PubMed]

32. Zhou, M.; Ren, F.; Li, J.; Ge, D.; Zhang, Y.; Chen, Z.; He, Y. Tunable Multi-Wavelength EDF Laser Based on Sagnac Interferometer with Weakly-Coupled FMF Delay Line. In Proceedings of the Optical Fiber Communication Conference, San Diego, CA, USA, 11-15 March 2018; pp. 7-9.

33. Luo, A.-P.; Luo, Z.-C.; Xu, W.-C. Tunable and switchable Multiwavelength Erbium-Doped Fiber Ring Laser Based on a Modified Dual-Pass. Opt. Lett. 2009, 34, 2135-2137. [CrossRef] [PubMed]

34. Lian, Y.; Ren, G.; Zhu, B.; Gao, Y.; Jian, W.; Ren, W.; Jian, S. Switchable multiwavelength fiber laser using erbium-doped twin-core fiber and nonlinear polarization rotation. Laser Phys. Lett. 2017, 14, 055101. [CrossRef] 
35. Yan, N.; Han, X.; Chang, P.; Huang, L.; Gao, F.; Yu, X.; Zhang, W.; Zhang, Z.; Zhang, G.; Xu, J. Tunable dual-wavelength fiber laser with unique gain system based on in-fiber acousto-optic Mach-Zehnder interferometer. Opt. Express 2017, 25, 27609. [CrossRef] [PubMed]

36. Zulkhairi, A.S.; Azzuhri, S.R.; Shaharuddin, R.A.; Jaddoa, M.F.; Salim, M.A.M.; Jasim, A.A.; Ahmad, H. Switchable multiwavelength ytterbium-doped fiber laser using a non-adiabatic microfiber interferometer. Laser Phys. 2017, 27, 055104. [CrossRef]

37. Ahmad, H.; Jasim, A.A. Stable C-band fiber laser with switchable multi-wavelength output using coupled microfiber Mach-Zehnder interferometer. Opt. Fiber Technol. 2017, 36, 105-114. [CrossRef]

38. Xu, Y.; Ren, L.; Ma, C.; Kong, X.; Ren, K.; Song, F. Stable and uniform multiwavelength erbium-doped fiber laser based on a microfiber knot resonator with a Sagnac loop reflector. J. Opt. 2017, 46, 420-424. [CrossRef]

39. Birks, T.A.; Li, Y.W. The Shape of Fiber Tapers. J. Lightw. Technol. 1992, 10, 432-438. [CrossRef]

40. Lopez-Dieguez, Y.; Estudillo-Ayala, J.M.; Jauregui-Vazquez, D.; Sierra-Hernandez, J.M.; Herrera-Piad, L.A.; Cruz-Duarte, J.M.; Hernandez-Garcia, J.C.; Rojas-Laguna, R. Multi-mode all Fiber Interferometer based on Fabry-Perot Multi-cavity and its Temperature Response. Opt. Int. J. Light Electron Opt. 2017, 147, $232-239$. [CrossRef]

41. Lopez-Dieguez, Y.; Estudillo-Ayala, J.M.; Jauregui-Vazquez, D.; Herrera-Piad, L.A.; Sierra-Hernandez, J.M.; Hernandez-Garcia, J.C.; Bienchetti, M.; Reyes-Ayona, J.R.; Rojas-Laguna, R. Tip Fiber-Optic Intermodal Interferometer for Refractive Index Sensing. IEEE Photonics Technol. Lett. 2018, 30, 15-18. [CrossRef]

42. Liu, X.; Yang, X.; Lu, F.; Ng, J.; Zhou, X.; Lu, C. Stable and uniform dual-wavelength erbium-doped fiber laser based on fiber Bragg gratings and photonic crystal fiber. Opt. Express 2005, 13, 142-147. [CrossRef] [PubMed]

43. Qhumayo, S.; Manuel, R.M.; Grobler, M. Wavelength and power stabilization of a three wavelength Erbium doped fiber laser using a nonlinear optical loop mirror. In Proceedings of the AFRICON, Addis Ababa, Ethiopia, 14-17 September 2015; pp. 1-4.

44. Lu, P.; Men, L.; Sooley, K.; Chen, Q. Tapered fiber Mach-Zehnder interferometer for simultaneous measurement of refractive index and temperature. Appl. Phys. Lett. 2009, 94, 131110. [CrossRef]

45. Chen, D.; Qin, S.; He, S. Channel-spacing-tunable multi-wavelength fiber ring laser with hybrid Raman and Erbium-doped fiber gains. Opt. Express 2007, 15, 930-935. [CrossRef] [PubMed]

46. Iu, L.; Ang, Z.H.Y. Tunable and channel spacing precisely controlled comb filters based on the fused taper technology. Opt. Express 2018, 26, 265-272.

47. Ummy, M.A.; Madamopoulos, N.; Joyo, A.; Kouar, M.; Dorsinville, R. Tunable multi-wavelength SOA based linear cavity dual-output port fiber laser using Lyot-Sagnac loop mirror. Opt. Express 2011, 19, 3202-3211. [CrossRef] [PubMed]

48. Wang, Z.; Wang, T.; Ma, W.; Jia, Q.; Su, Q.; Zhang, P. Optical Fiber Technology Tunable multiwavelength Brillouin-Raman fiber laser in a linear cavity with spectrum reshaped by Rayleigh scattering. Opt. Fiber Technol. 2017, 36, 327-333. [CrossRef]

49. Yang, J.; Tjin, S.C.; Ngo, N.Q. Multiwavelength Tunable Fiber Ring Laser Based on Sampled Chirp Fiber Bragg Grating. IEEE Photonics Technol. Lett. 2004, 16, 1026-1028. [CrossRef]

(C) 2018 by the authors. Licensee MDPI, Basel, Switzerland. This article is an open access article distributed under the terms and conditions of the Creative Commons Attribution (CC BY) license (http:// creativecommons.org/licenses/by/4.0/). 